\title{
Body piercing and self-mutilation: A multifaceted relationship
}

\author{
Anika Wessel $^{1}$, Erich Kasten ${ }^{2}$ \\ ${ }^{1}$ Dept. of Internal Medicine, Johanniter Hospital Geesthacht, Geesthacht, Germany \\ ${ }^{2}$ Dept. of Neuropsychology, Medical School Hamburg, University of Applied Sciences, Hamburg, Germany \\ Email address: \\ anika-wessel@web.de (A. Wessel), EriKasten@aol.com (E. Kasten)
}

\section{To cite this article:}

Anika Wessel, Erich Kasten. Body Piercing and Self-Mutilation: A Multifaceted Relationship. American Journal of Applied Psychology. Vol. 3, No. 4, 2014, pp. 104-109. doi: 10.11648/j.ajap.20140304.14

\begin{abstract}
Goal was to examine the connection between piercings and self-mutilation and the practice of self-piercing. Participants $(\mathrm{n}=140)$ completed an anonymous online survey consisting of a 54-item questionnaire and a standardized personality test. All respondents were members of internet communities specialized on piercings. The majority of participants $(77.1 \%)$ were female, $22.9 \%$ were male. The mean age of the group was 24.7 years (range: 16-57 years). Participants had an average of 8.9 piercings. More than half (57.9\%) of participants were between 15 and 20 years old when they acquired their first piercing. The most common piercings reported were facial (in $82.9 \%$ of participants), ear cartilage (in $67.9 \%$ of participants), nipple (in $48.6 \%$ of participants) and genital piercings (in $45.0 \%$ of participants). Participants were asked to complete the NEO-FFI personality inventory, which is a tool used to measure the personality factors Conscientiousness, Agreeableness, Extraversion, Openness and Neuroticism. Although all of the NEO-FFI results were within the average norm, significant differences between the participants with/without self-injury were found regarding the T-Scores for Neuroticism and Agreeableness. Thirty-one percent of the participants reported a history of self-mutilation. Those with a history of self-mutilation did not have more piercings than their peers. Half of these individuals described a decrease in auto-aggressive behavior since having acquired piercings, twenty-five percent claim to have ceased self-injurious behavior. The incidence of self-mutilation appears to be higher among pierced individuals than among the general public. Participants who had engaged in self-injury had significantly more often self-pierced. Piercings and self-piercings may serve as substitute behavior for self-mutilation in some individuals.
\end{abstract}

Keywords: Body Piercing, Self-Mutilation, Self-Piercing

\section{Introduction}

Body modification has been dated back to as early as 3000 BC. The Tyrolean Iceman, which was found in the Italian Alps in 1991 and is thought to be 5250 years old, had several tattoos on his body [1]. Urban tribes such as the Maori, the Aborigines and the Mursi were known for applying piercings, tattoos and scarifications to their bodies. The procedures were often performed as part of the ceremonial transition from adolescence to adulthood, marriage or to cherish an important milestone in one's life such as the birth of a woman's first child [2]. Body piercing first became popular in western culture among the so called "punk movement" during the 1970 s before it became a mass phenomenon, which extended across a broader segment of society [3].
Piercings are not always solely acquired for the purpose of embellishment. A review published by Wohlrab, Stahl \& Kappeler focused on these common motivational statements for acquiring piercings: "Beauty, art and fashion", "individuality", "personal narrative", "physical endurance", "group affiliations and commitment", "resistance", "spirituality and cultural transition", "addiction" and "sexual motivation". In a study by Forbes participants considered "self-expression", "to be different" and "I just like the looks of it" to be the most important reasons to acquire piercings [4], whereas the predominant motives for piercings, in general, seem to be beautification of the body and expression of individuality according to Wohlrab, Stahl \& Kappeler [5]. A number of studies have suggested that some 
individuals use body modifications to cope with stress and trauma $[6,7,8]$.

Piercings were present in $10 \%$ of individuals aged 16 or over $(n=10,508)$ in a study by Bone, Ncube, Nichols \& Noah in England in 2005 [4]. The body parts most frequently pierced were nose, ear (not lobe) and navel [9]. Stirn, Hinz \& Brähler found piercings in $6.8 \%$ of individuals $(n=2,512)$ in Germany in 2006 [10]. The highest prevalence of piercings is found in the age group 16-24 and most, but not all, piercings are performed by professionals. Bone, Ncube, Nichols \& Noah revealed that while $80.5 \%$ of piercings reported in their study were acquired from specialist piercing shops, a small percentage (3.4\%) were performed by friends or relatives and a slightly larger number $(5.4 \%)$ of participants had self-pierced (the classifications "Mobile piercers", "Another shop" and "Other" accounted for the rest of the piercings performed by non-professionals) [9]. In a study by Stirn \& Hinz $89 \%$ of participants reported that they had acquired their piercings or tattoos from a professional. Among those who admitted to self-cutting significantly fewer individuals had acquired their piercings from professionals [8].

Self-mutilation, self-harm or self-injury is the intentional injuring of body tissue. It can occur in various forms including cutting, burning, interference with wound healing and ingestion of objects or substances. The reasons for self-injury are multifaceted and include affect regulation, sensation-seeking and self-punishment. According to Klonsky \& Muehlenkamp [11] self-injury is most often utilized in order to "temporarily alleviate intense negative emotions". According to Klonsky, Oltmanns \& Turkheimer [12] $4 \%$ of individuals in the general public report a history of self-injury; Klonsky \& Muehlenkamp concluded that adolescents and young adults are at greatest risk for self-injury [11]. In a British study by Hawton, Rodham, Evans \& Weatherall $6.9 \%$ of their 15 - 16 year old participants reported an act of deliberate self-harm. Self-harm appears to be more common in females than in males, though some studies have concluded that there are no differences between the genders regarding the incidence of self-mutilation $[11,13]$.

The tendency towards self-mutilation appears to be higher in the body modification community. In a study by Stirn \& Hinz, $34 \%$ of the body-modified participants (the sample included pierced and tattooed subjects) admitted to self-cutting in their childhood. Interestingly, among these individuals, $13 \%$ reported that they stopped cutting themselves completely and an unspecified number of participants reported a decrease in self-injurious behavior after acquiring body modifications. Self-mutilators reported significantly more piercings than non self-mutilators. While discussing the decrease in self-mutilation, the authors stated that there were indicators that participants "used BM [body modifications] as a substitute for their auto-aggressive acts" [8].

While Forbes had found no significant differences between body-modified an non body-modified individuals regarding the "Big Five" personality factors Neuroticism, Agreeableness, Conscientiousness, Extraversion and Openness [4] and Stirn, Hinz \& Brähler found "no significant difference between body-modified and non-body-modified respondents regarding depression or anxiety" [10], a recent study by D'Ambrosio, Casillo \& Martini presented data suggesting that the presence of piercings and tattoos was "linked to emotional distress and to the need of using the body to express concern, discomfort, anger and loneliness" and "correlated [...] with psychological and personality disorders (i.e. borderline personality disorder)" in the subjects examined [14].

The current study sought to examine the relationship between piercings, self-piercings and self-mutilation. In keeping with the notion that piercings may serve as a substitute for self-injurious behavior, it was examined whether participants with a history of self-mutilation report a decrease in self-mutilation since having acquired piercings. Furthermore, it was proposed that participants with a history of self-mutilation self-pierce, rather than seek a professional, more often than their peers who never engaged in self-mutilation. Intuitively, those who have shown self-injurious behavior in the past are more likely to engage in self-piercing. For individuals with a tendency towards self-injury self-piercing may be a form of satisfying their self-mutilating drive.

\section{Methods}

\subsection{Participants}

By design, this study was intended to investigate a sample in which the prevalence of piercings is $100 \%$. To locate a sufficient number of pierced individuals, members of internet communities specialized on piercings were recruited. In all, 418 individuals were contacted during May and June of 2011.

\subsection{Questionnaire}

A self-report questionnaire containing 54 questions was designed. The following demographic data was collected: sex, age, weight, height, highest level of education and profession. The questionnaire was divided into 6 theoretical sections: general piercing history information (2 questions), planning and acquisition of piercings (12 questions), reactions to piercings and contact to peers (6 questions), motives for piercings ( 7 questions), change in attractiveness, self-confidence and self-mutilation (18 questions), removal of piercings ( 9 questions). The questions were answered by multiple-choice (26 questions), by reporting a numerical value (7 questions) and by positioning a slider on a qualitative scale (21 questions). Respondents were asked to complete the questionnaire as well as a standardized online personality test, the NEO-FFI (NEO Five-Factor Inventory) which was designed to measure the personality factors Neuroticism, Agreeableness, Conscientiousness, Extraversion and Openness [15]. 


\subsection{Analysis Should this Be Moved to the Next Page?}

Ultimately, 140 questionnaires could be used for analysis. Initial analysis was done by the conductor of the study in July and August 2011. Further calculations were done between October 2013 and February 2014 in collaboration with an employee of the Universität zu Lübeck's Institute for Medical Biometry and Statistics.

\subsection{Limitations of the Data}

Numerous studies on the prevalence of piercings in the general public or preselected groups of students have been conducted in the past. This study sought to examine a sample in which the prevalence of piercings is $100 \%$. The participants of this study were recruited from internet communities specialized on piercings. Because only a sub-group of the piercing community was examined, parameters such as average number of piercings, locations of piercings and statements concerning self-mutilation may not be transferable onto the general group of pierced individuals. Individuals who acquire piercings are likely to emphasize the positive effects associated with piercings while they may underestimate negative effects such as complications [2]. This is consistent with findings in cognitive bias research which indicate that individuals tend to weight evidence consistent with decisions they have made more heavily and assign less value to data which are contrary to the position they have taken in order to avoid cognitive dissonance [16].

Gender quotas were not pre-defined in the design of this study. Previous studies $[2,9,10]$ have shown that piercings are more common among females. The design of the study excluded individuals who only had earlobe piercings. This exclusion criterion is common in studies regarding body piercing, because earlobe piercings are a common fashion accessory across many cultures and age groups $[2,4]$.

\section{Results}

\subsection{Characteristics of the Sample}

Of the 140 participants $108(77.1 \%)$ were female, 32 $(22.9 \%)$ were male. The mean age of the group was 24.7 years (range: 16-57 years). Participants had an average of 8.9 piercings (range: $1-102$ piercings). The majority, $57.9 \%$, of participants were between 15 and 20 years old when they acquired their first piercing. About a quarter of participants, $26.4 \%$, were 14 years of age or younger (see Fig. 1). The most common piercings reported were facial (in $82.9 \%$ of participants), ear cartilage (in $67.9 \%$ of participants), nipple (in $48.6 \%$ of participants) and genital piercings (in $45.0 \%$ of participants). Fig. 2 shows the locations which were pierced at least once (the exact number of piercings in each location is not illustrated in this figure) at the point of survey. Participants were given the option of identifying multiple piercing locations.

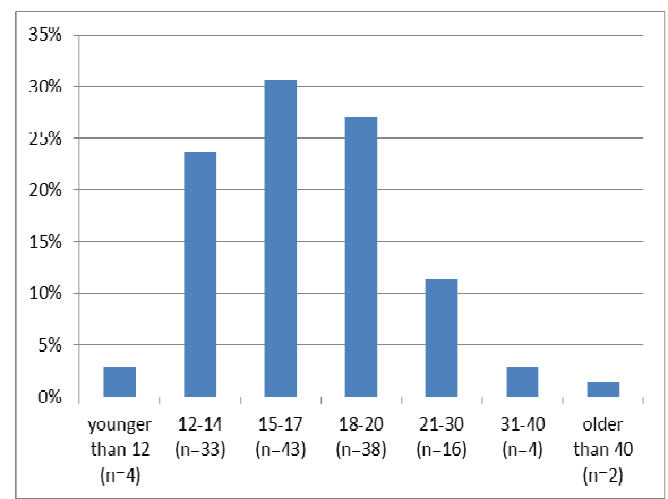

Figure 1. Age at which first piercing was acquired $(n=140)$

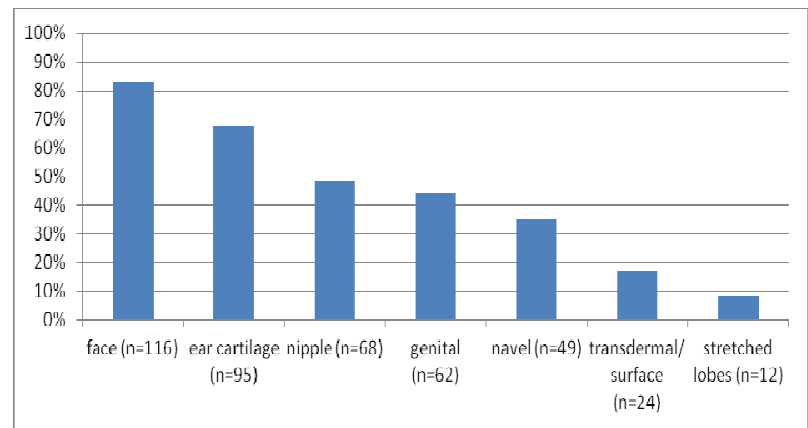

Figure 2. Piercing locations/ types of piercings present in participants $(n=140)$

Participants were asked to select their motives for the acquisition of piercings from a list of options. The primary motives named by participants are shown in Table 1. The motivations "body art", "to underline my identity" and "to be more attractive", were identified as the primary reasons to acquire piercings.

Table 1. Motives for piercings $(n=139)$

\begin{tabular}{lll}
\hline Category & frequency & percentage \\
\hline Body art & 47 & 33.8 \\
To underline my identity & 42 & 30.2 \\
To be more attractive & 20 & 14.3 \\
Sexual motives & 12 & 8.6 \\
To mark an event or phase & 8 & 5.7 \\
Protest, rebellion & 2 & 1.4 \\
To become more independent & 2 & 1.4 \\
Out of curiosity & 2 & 1.4 \\
To test my borders & 2 & 1.4 \\
To test my ability to handle pain & 1 & 0.7 \\
other & 1 & 0.7 \\
\hline
\end{tabular}

\subsection{Personality Traits}

Participants were asked to complete the NEO-FFI personality inventory, which is a tool used to measure the personality factors Conscientiousness, Agreeableness, Extraversion, Openness and Neuroticism. The mean NEO-FFI results of the entire group $(n=140)$ were within the norm (defined by the publishers of the NEO-FFI as T-Score $50 \pm 10$ ). 
Due to the high percentage of self-mutilators $(31.4 \%$, $\mathrm{n}=44)$ within the subject pool $(\mathrm{n}=140)$, and interest in factors which might differentiate those individuals from the non self-mutilating participants, the subject pool was then divided into two sub-groups: those who had engaged in self-mutilation vs. those who had not. The NEO-FFI T-Scores for the two resulting sub-groups were further examined. The results are shown in Table 2.

Table 2. NEO-FFI T-Scores by self-mutilation/no self-mutilation $(n=140)$

\begin{tabular}{llll}
\hline Personality trait & $\begin{array}{l}\text { self-mutilation } \\
\text { T-Score } \pm \text { SE } \\
(\mathbf{n = 4 4 )}\end{array}$ & $\begin{array}{l}\text { no self-mutilation } \\
\text { T-Score } \pm \text { SE } \\
(\mathbf{n = 9 6 )}\end{array}$ & $\begin{array}{l}\mathbf{p} \\
\text { (t-test) }\end{array}$ \\
\hline Conscientiousness & $43.89 \pm 1.73$ & $44.92 \pm 1.09$ & 0.610 \\
Agreeableness & $41.82 \pm 1.80$ & $46.61 \pm 1.12$ & $\mathbf{0 . 0 2 1 *}$ \\
Extraversion & $46.84 \pm 1.78$ & $50.27 \pm 1.19$ & 0.110 \\
Openness & $53.80 \pm 1.91$ & $51.60 \pm 1.00$ & 0.312 \\
Neuroticism & $58.91 \pm 1.14$ & $51.19 \pm 1.15$ & $\mathbf{0 . 0 0 0 * *}$ \\
\hline
\end{tabular}

Although all T-Scores were within the overall norm for the NEO-FFI, significant differences between the two sub-groups were found regarding the T-Scores for Neuroticism and Agreeableness. The scores for Conscientiousness, Extraversion and Openness did not differ significantly between the two groups.

\subsection{Self-Mutilation}

Within this study's subject pool, nearly one third of participants, $31.4 \% \quad(n=44)$, admitted to self-mutilation. Self-mutilation was significantly (chi-squared test, $\mathrm{p}<0.05$ ) more common among female participants. Self-mutilation was reported by $36.1 \%(n=39)$ of female respondents while only $15.6 \%(n=5)$ of males reported such behavior. Those with a history of self-mutilation did not have more piercings than their peers (see Table 3). Individuals, who reported acts of self-mutilation, were asked whether their self-mutilating behavior has changed since acquiring piercings and further, whether it has increased, decreased or ceased. Fifty percent $(n=22)$ of the participants with a history of self-mutilation stated that since acquiring piercings their self-injurious behavior has decreased. Twenty-five percent $(n=11)$ reported that they ceased self-mutilation after the acquisition of piercings. On the contrary, $6.8 \%$ of the participants $(n=3)$ reported an increase in self-mutilation. Eighteen percent $(\mathrm{n}=8)$ reported "no change". Overall $75 \%$ $(n=33)$ of the participants with self-injurious behavior reported a decrease in self-mutilating behavior (see Fig. 3).

Table 3. Self-mutilation and average number of piercings

\begin{tabular}{llll}
\hline Characteristics & $\begin{array}{l}\text { self-mutilators } \\
(\mathbf{n = 4 3 )}\end{array}$ & $\begin{array}{l}\text { non } \\
\text { self-mutilators } \\
(\mathbf{n = 9 6 )}\end{array}$ & $\begin{array}{l}\text { Total } \\
(\mathbf{n = 1 4 0 )}\end{array}$ \\
\hline $\begin{array}{llll}\text { Number of piercings } \\
\pm \mathrm{SE}\end{array}$ & 9.39 & 7.64 & 8.84 \\
\pm 1.20 & \pm 0.82 & \pm 10.20 \\
\hline
\end{tabular}

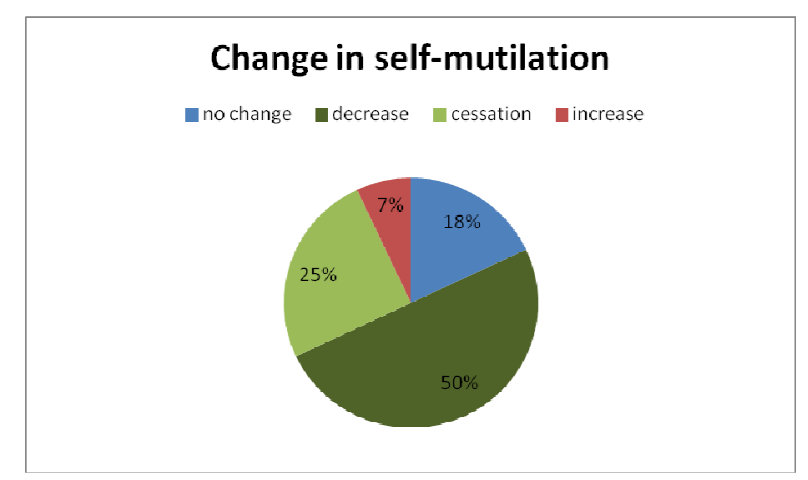

Figure 3. Change in self-mutilation after acquisition of piercings $(n=44)$

\subsection{Self-Piercing}

Among all participants $43.8 \%$ of the males (15 out of 32 ) and $27.8 \%$ of the females (30 out of 108 ) admitted to having pierced themselves (self-piercing). This gender difference in self-piercing behavior was significant (chi-squared test, $\mathrm{p}<0.05$ ).

Participants were asked whether they had ever self-pierced and if they had ever engaged in self-mutilation. They were divided into groups according to their answer and compared using a chi-squared test. Those who had a history of self-mutilation self-pierced significantly more often $(p<0.01)$ than the participants who had no history of self-mutilation. The data is illustrated in Table 4.

Table 4. Self-piercing and self-mutilation $(n=140)$

\begin{tabular}{llll}
\hline Characteristics & self-mutilators & non self-mutilators & total \\
\hline have self-pierced & $21(47.7 \%)$ & $24(25.0 \%)$ & 45 \\
have not self-pierced & $23(52.3 \%)$ & $72(75.0 \%)$ & 95 \\
total & 44 & 96 & 140 \\
\hline
\end{tabular}

\section{Discussion}

This study was conducted among a highly dedicated sub-group within the piercing population. The average number of piercings was higher in this study than in other studies. This was most likely due to the fact that all participants were active members of specialized online piercing communities and therefore constituted a sub-group for which piercing was a more significant factor in their lives than for other, lesser-pierced, individuals. These individuals may, intuitively, take part in body modification to a more extreme extent than the average pierced individual. Aside from the higher average number of piercings, a further indicator, that subjects in this sample were more dedicated to piercings than average pierced individuals, may be, that more than $80 \%$ of this study's participants had facial piercings whereas, in the large study by Bone, Ncube, Nichols \& Noah only about $40 \%$ of pierced individuals had facial piercings [9].

The primary motives for acquiring piercings in the current study were: "to be more attractive", "body art" and "to underline my identity". These findings support the 
conclusions drawn in the large review study by Wohlrab, Stahl \& Kappeler [5].

When the current sample, consisting of individuals highly engaged in the piercing community, was considered as a whole, no psychological abnormalities in terms of the personality factors Neuroticism, Agreeableness, Conscientiousness, Extraversion and Openness were found using the NEO-FFI. This finding expands upon data by Forbes, who reported that body-modified individuals did not differ from non body-modified individuals regarding the Big Five personality factors [Neuroticism, Agreeableness, Conscientiousness, Extraversion and Openness] within the college population he examined [4]. When the sub-group of self-mutilators was compared to the non self-mutilators within the current sample, we found that these subjects scored significantly higher on the NEO-FFI Neuroticism and Agreeableness scales than our other subjects, although their scores were still within the population norm. This finding suggests the need for further examination of these sub-groups using a wider range of psychological measures.

Self-mutilation was relatively common among participants of this study $(31.4 \%)$. The hypothesis that the acquisition of piercings leads to a self-reported decrease in self-mutilation was supported by the data collected in the current study. Half (50.0\%) of the self-mutilators within our sample stated that they have been injuring themselves less since having acquired piercings. A quarter (25.0\%) reported that they have ceased self-mutilation altogether. Our findings, while generally consistent with the findings reported by Stirn \& Hinz [8], appear to have far exceeded their self-mutilation reduction rates. Thirteen percent of their subjects reported that they had ceased self-mutilation and an unspecified number (specific value not reported) reported reduction in self-mutilation. The authors postulated that acquiring piercings may act as a substitute for self-injury for some individuals. It should be noted that the body modified subjects in the study by Stirn \& Hinz included both pierced and tattooed individuals and likely represented a different group than our subjects. While Stirn \& Hinz had found self-cutters to have significantly more piercings than others [8], we found a numerical, although not significant, difference in a direction which is opposite to the findings reported by Stirn \& Hinz within our subject set. Specifically, our self-mutilating subjects reported fewer piercings than the non self-mutilators (average number of piercings $=7.6$ in self-mutilators vs. 9.4 in non self-mutilators). While no conclusions can be drawn from these findings, both the lack of overall significance and the counter-intuitive inversion of the number of piercings within the self-mutilators vs. non self-mutilators, suggest the need for further study of this question and greater explication of the relationship between number of piercings and self-mutilation.

The positive effect of piercings on self-injurious behavior, which resulted in a decrease of self-mutilation in a large fraction of self-mutilators in the current study was not universal among participants. Interestingly, in a subset (7\%) of this group the acquisition of piercings was related to an increase in self-mutilation. Ways in which this sub-group differed from the rest of the sample and which intervening variables may account for the increase in self-harm activity should be investigated in further research. Stirn \& Hinz had postulated that for some self-mutilators, body piercing becomes a more acceptable substitute behavior for self-injury [8]. Considering piercing as a form of self-mutilation led to the question of whether self-mutilators more frequently self-pierce, rather than use the services of a piercing establishment. Based on the data collected, we were not able to examine the relationship between self-mutilation and the number of self-piercings. We did, however, compare the presence or absence of a self-piercing history, among the self-mutilating and non-self-mutilating sub-groups.

Self-piercing was described by $32.1 \%$ of the respondents. Self-mutilators admitted to self-piercing significantly more often than non-self-mutilators. Further, the high incidence of self-piercing among self-mutilators was interpreted as an indicator that piercings may indeed be used as a substitute for self-injury. This consideration challenges the idea that an actual reduction in self-injurious behavior took place, despite the fact that such a phenomenon is suggested by the overall decrease in self-mutilation reported by the affected individuals. Rather, we suspect that within this group there had, in fact, simply been a substitution of piercing/self-piercing for self-injury. Ultimately, whether or not a true reduction of self-injury actually occurred following the acquisition of piercings, remains unclear at the end of the current study. It can certainly be argued that piercing may constitute a more "acceptable" and less hazardous form of self-mutilation, especially if performed in hygienic and controlled conditions.

\section{Conclusion}

Our findings suggest the need for a more careful examination of the psychological roots of piercing and self-piercing behavior, especially regarding the two sub-groups (self-mutilating and non self-mutilating individuals) using a broader spectrum of psychological measures in order to gain a better understanding of the complex motivators at work and an accurate picture of the relationship between piercing, self-piercing, self-mutilation and the driving psychological factors at play.

A self-reported positive impact of piercings on self-mutilation, that is a decrease in self-injurious behavior as a consequence of the acquisition of piercings, was described in previous studies and largely supported by the data collected in the current study. While this can be interpreted as an overall positive finding, the significant relationship between self-mutilation and reports of self-piercing is alarming and supports the thesis that the piercings themselves may, in some, serve as a form of self-mutilation. 


\section{Acknowledgements}

The authors thank all participants of this study for their contribution and the Universität zu Lübeck's Institute for Medical Biometry and Statistics for their help in the statistical analysis of the data.

\section{References}

[1] Keller, A. et al. (2012). Nature Communications. New insights into the Tyrolean Iceman's origin and phenotype as inferred by whole-genome sequencing:

http://www.nature.com/ncomms/journal/v3/n2/full/ncomms 1701.html

[2] Kasten, E. (2006). Body Modification: Psychological and medical aspects of piercing, tattoo, self-mutilation and other forms of body-modification (Body-Modification: Psychologische und medizinische Aspekte von Piercing, Tattoo, Selbstverletzung und anderen Körperveränderungen). München: Reinhardt.

[3] Kasten, E. (2007). Genital body modification in women (Genitale Body-Modifications bei Frauen). Der Gynäkologe, 40(6): 489-500.

[4] Forbes, G. B. (2001). College students with tattoos and piercing: motives, family experiences, personality factors and perception by others. Psychological Reports, 89(3): 774-786.

[5] Wohlrab, A., Stahl, J., \& Kappeler, P. (2007). Modifying the body: motivations for getting tattoed and pierced. Body Image, 4(1): 87-95.

[6] De Mello, M. (2000). Bodies of inscription. A cultural history of the modern tattoo community. Durham, NC: Duke University Press.
[7] Hewitt, K. (1997). Mutilating the body. Identity in blood and ink. Bowling Green State University Popular Press.

[8] Stirn, A., \& Hinz, A. (2008). Tattoos, body piercings, and self-injury: Is there a connection? Psychotherapy Research, 18(3): 326-333.

[9] Bone, A., Ncube, F., Nichols, T., \& Noah, N. (2008). Body piercing in England: a survey of piercing sites other than the earlobe. British Medical Journal, 336(7658): 1426-1428.

[10] Stirn, A., Hinz, A., \& Brähler, E. (2006). Prevalence of tattooing and body piercing in Germany and perception of health, mental disorder, and sensation seeking among the tattoed and body-pierced individuals. Journal of Psychosomatic Research, 60(5): 531-534.

[11] Klonsky, E., \& Muehlenkamp, J. (2007). Self-Injury: a research review for the practitioner. Journal of Clinical Psychology, 63(11): 1045-1056.

[12] Klonsky, E., Oltmanns, T., \& Turkheimer, E. (2003). Deliberate self-harm in a nonclinical population: Prevalence and Psychological Correlates. American Journal of Psychiatry, 160(8): 1501-1508.

[13] Hawton, K., Rodham, K., Evans, E., \& Weatherall, R. (2002). Self-harm in adolescents: self-report survey in schools in England. British Medical Journal, 325(7374): 1207-1211.

[14] D'Ambrosio, A., Casillo, N., \& Martini, V. (2013). Piercings and tattoos: psychopathological aspects. Activitas Nervosa Superior Rediviva, 55(4):143-148.

[15] Borkenau, P., \& Ostendorf, F. (1993). NEO Five-Factor Inventory (NEO-FFI) (NEO-Fünf-Faktoren-Inventar (NEO-FFI)) nach Costa und McCrae. Hogrefe.

[16] Mahoney, M. (1977). Publication Prejudices: an experimental study of confirmatory bias in the peer review system. Cognitive Therapy and Research, 1(2): 161-175. 